\title{
Isolamento de Salmonella enterica em gambás (Didelphis aurita e Didelphis albiventris) do Estado de São Paulo, Brasil
}

\author{
Isolation of Salmonella enterica in opossum (Didelphis aurita and Didelphis albiventris) of the São \\ Paulo State, Brazil
}

\author{
Renata Assis Casagrande ${ }^{\mathrm{I}}$ Luiz Fernando Larangeira Lopes ${ }^{\mathrm{I}}$ Eliane Moura dos Reis ${ }^{\mathrm{II}}$ \\ Dália dos Prazeres Rodrigues ${ }^{\mathrm{II}}$ Eliana Reiko Matushima ${ }^{\mathrm{I}^{*}}$
}

\section{RESUMO}

No Brasil, não há relato de estudos de Salmonella em gambás, sendo assim, este trabalho tem por objetivo determinar a frequência de isolamento de Salmonella enterica em gambás (D. aurita e D. albiventris) no Estado de São Paulo. No período de janeiro de 2005 a dezembro de 2006, foram necropsiados $106 \mathrm{D}$. aurita e $40 \mathrm{D}$. albiventris e colhidos fragmentos de intestinos delgado, grosso e suabe da cloaca. As amostras foram plaqueadas diretamente em ágar Mac Conkey, paralelamente suspendidas nos caldos RappaportVassiliadis e Tetrationato e posteriormente plaqueados em ágar XLT4. As colônias sugestivas de Salmonella foram confirmadas através de provas bioquímicas e sorotipagem. Encontrou-se Salmonella enterica em 17,0\% (18/106) dos D. aurita. Destes, $50 \%$ apresentaram positividade no intestino delgado (ID), $88,9 \%$ no intestino grosso (IG) e 66,7\% na cloaca. Da espécie S. enterica, as subespécies encontradas foram: diarizonae $(11,1 \%)$ houtenae e enterica $(5,5 \%$ cada um); enquanto da subespécie $S$. enterica enterica os sorotipos foram Newport (83,3\%), Typhimurium e Cerro (5,5\% cada um). Nos D. albiventris, $17,5 \%$ (7/40) eram positivos, sendo que se encontraram $42,8 \%$ no ID, $85,7 \%$ no $I G$ e $71,4 \%$ na cloaca. $O$ sorotipo mais prevalente também foi Newport $(71,4 \%)$, seguido por Typhimurium, Bareilly e Thompson (14,3\% cada um). Através dos resultados obtidos neste estudo pode-se comprovar a presença de Salmonella enterica no trato intestinal de gambás no Brasil.

Palavras-chave: Salmonella enterica, gambá, zoonose, Brasil.

\section{ABSTRACT}

In Brazil there is not report of Salmonella in opossum, so then, the objective of this study is to determine the isolation frequency of Salmonella enterica in opossum in São Paulo State, Brazil. From January 2005 to December 2006, $106 \mathrm{D}$. aurita and $40 \mathrm{D}$. albiventris were necropsied and samples from small and large intestine and cloacal swab were collected. These samples were submitted to direct plating in Mac Conkey agar and parallel suspension in RappaportVassiliadis and Tetrationate broths with posterior streaking in XLT4 agar. The characterization of the isolates was done through biochemical tests and serotyping. Salmonella enterica was found in $17.0 \%$ (18/106) of the D. aurita; $50 \%$ presented the bacteria in the small intestine (SI), $88.9 \%$ in the large intestine (LI) and $66.7 \%$ in the cloaca. Of the S. enterica were found the subspecies: diarizonae (11.1\%), enterica and houtenae $(5.5 \%$ each); and the serotypes of the S. enterica enterica were Newport (83.3\%), Typhimurium and Cerro (5.5\% each). In the D. albiventris $17.5 \%$ (7/40) were positive; $42.8 \%$ in the SI, $85.7 \%$ in the LI and $71.4 \%$ in the cloaca. Newport (71.4\%) was also the most frequent serotype and the second were Typhimurium, Bareilly and Thompson (14.3\% each). The presence of Salmonella enterica in the intestines of opossums in Brazil was proved.

Key words: Salmonella enterica, opossum, zoonosis, Brazil.

\section{INTRODUÇÃO}

Os gambás pertencem ao gênero Didelphis que é composto por cinco espécies, sendo elas: $\boldsymbol{D}$. virginiana que tem distribuição da América do Norte até América Central (HUNSAKER, 1977); D. marsupialis com localização da América no Norte até a América do Sul; D. aurita, D. albiventris e

IDepartamento de Patologia Veterinária, Faculdade de Medicina Veterinária e Zootecnia (FMVZ), Universidade de São Paulo (USP), Avenida Orlando Marques de Paiva, 87, 05508-900, São Paulo, SP, Brasil. E-mail: ermatush@usp.br. *Autor para correspondência.

IIDepartamento de Bacteriologia, Fundação Oswaldo cruz (FIOCRUZ), Rio de Janeiro, RJ, Brasil. 
D. imperfecta que ocorrem na América do Sul (CERQUEIRA, 1985; CERQUEIRA \& LEMOS, 2000). Este é um dos gêneros de mamíferos mais extensamente distribuído no continente americano, perdendo apenas para a espécie humana e também o gênero de marsupial mais distribuído do mundo (HUNSAKER, 1977).

Os animais pertencentes a esse gênero são extremamente adaptáveis aos mais diferentes ambientes, como florestas e em meio à civilização humana. São nômades, sendo difícil definir seu território, pois percorrem longas distâncias e permanecem em uma área por períodos relativamente curtos, facilitando assim a disseminação de patógenos (FINNIE, 1986).

A Salmonella é considerada um agente patogênico para o homem e os animais domésticos (CAMPOS, 1999). O D. virginiana serve como reservatório de vários sorotipos na natureza e pode ter um papel importante na epidemiologia das salmoneloses de animais selvagens de vida livre (TRIGPEN \& MOORE, 1975; RUNKEL et al., 1991; ADESIYUN et al., 1998; PIÑA et al., 2002). Estudos realizados em Trinidad mostraram que a prevalência de Salmonella spp. em D. marsupialis foi significantemente mais elevada em Agouti paca (paca), Mazama americana (veado-mateiro), Dasyprocta leporina (cutia), Dasypus novemcinctus (tatu-galinha) e Tayassu tajacu (porco do mato) (ADESIYUN et al., 1998).

Os gambás podem transmitir Salmonella spp. para outros animais e seres humanos pelas fezes, através do contato direto ou indireto. Essas podem contaminar a água consumida por humanos ou ração e água utilizados para a alimentação dos animais de produção e secundariamente ser transmitida através da carne (VILLAFAÑE et al., 2004), ou, ainda, quando utilizada para irrigar as hortaliças (OROZCO et al., 2008).

No Brasil, não há relato de estudos de Salmonella spp. em gambás. Este trabalho tem por objetivo determinar a frequência de isolamento de Salmonella enterica em D. aurita e D. albiventris no Estado de São Paulo.

\section{MATERIAL E MÉTODOS}

No período correspondente a janeiro de 2005 a dezembro de 2006, foram recebidos cadáveres de marsupiais sul-americanos do gênero Didelphis, sendo 106 D. aurita e 40 D. albiventris, provenientes do Zoológico Municipal Quinzinho de Barros, Sorocaba SP(45 animais), DEPAVE-3 Fauna (Departamento de Parques e Áreas Verdes), São Paulo - SP(40 animais), Zoológico de São Bernardo do Campo, São Bernardo SP (31 animais), Orquidário de Santos, Santos - SP (24 animais), Parque Ecológico do Tiête, São Paulo - SP (4 animais) e do CEMAS (Centro de Manejo de Animais Silvestres), São Paulo - SP (2 animais).
Os gambás foram transportados até o Laboratório de Patologia Comparada de Animais Silvestres (LAPCOM) do Departamento de Patologia (VPT) da Faculdade de Medicina Veterinária e Zootecnia da Universidade de São Paulo (FMVZ-USP) para realização de necropsia. Esses foram mantidos sob refrigeração e a necropsia foi efetuada no período máximo de 24 horas após a morte natural ou eutanásia, realizada nos locais de origem. Eles foram classificados quanto à espécie, sexo e faixa etária que era calculada de acordo com a dentição, segundo PETRIDES (1949). Classificaram-se como filhotes, os gambás que tinham tamanho inferior ao de adulto e dentição incompleta, subadultos os que apresentavam tamanho semelhante ao de adulto, porém com dentição incompleta e adultos quando possuíam tamanho e dentição completa.

Durante a necropsia, foram colhidos fragmentos de intestinos delgado, grosso e suabe da cloaca para realização de exame microbiológico. Após este procedimento, todos os suabes foram imediatamente introduzidos em tubo com meio de transporte Stuart e mantidos sob refrigeração a $4^{\circ} \mathrm{C}$ por um período máximo de 24 horas. Esses suabes foram colocados em tubo estéril contendo $1 \mathrm{~mL}$ de solução salina e a seguir plaqueado em ágar Mac Conkey (MC). Da solução salina, $0,5 \mathrm{~mL}$ foi inoculado em $10 \mathrm{~mL}$ de caldo Rappaport-Vassiliadis (RV) e $0,5 \mathrm{~mL}$ em $10 \mathrm{mLde}$ caldo Tetrationato (TT). As placas de ágar MC e os tubos com caldo TT eram incubados a $37^{\circ} \mathrm{C}$ e os tubos de caldo $\mathrm{RV}$ a $42^{\circ} \mathrm{C}$.

Após 24 horas, analisaram-se as placas de MC e as colônias lactose negativas com morfologia compatível com Salmonella sp. foram selecionadas para identificação bioquímica presuntiva. Os tubos de caldo $\mathrm{RV}$, após 24 horas, eram plaqueados em ágar XLT4 e os de TT após 48 horas, sendo todos incubados a $37^{\circ} \mathrm{C}$. Depois das 24 horas, as colônias enegrecidas sugestivas de Salmonella sp. foram isoladas para identificação presuntiva.

A identificação presuntiva dessas colônias era realizada através das seguintes provas bioquímicas: triple sugar iron agar (TSI), lisine iron agar (LIA), motility, indole, ornithine (MIO) e caldo uréia incubados por 24 horas a $37^{\circ} \mathrm{C}$. As colônias cujas provas bioquímicas eram compatíveis com Salmonella sp. foram submetidas à identificação bioquímica definitiva com as seguintes provas bioquímicas: ágar citrato e fenilalanina, oxidação de açúcares (lactose, sacarose, manitol, arabinose, sorbitol e maltose), verificação de produtos metabólicos oriundos da fermentação da glicose (acetoína: VP e ácidos fortes: VM) e produção de gelatinase.

As colônias cujas provas bioquímicas completas eram compatíveis com Salmonella sp. foram enviadas para sorotipagem em laboratório de referência, 
neste caso, no Laboratório de Enterobactérias do Departamento de Bacteriologia, do Centro de Referência Nacional de Cólera e outras Enteroinfecções Bacterianas da Fundação Instituto Oswaldo Cruz FIOCRUZ, Estado do Rio de Janeiro. A caracterização dos sorotipos de Salmonella foi realizada por detecção dos antígenos somáticos e flagelares, utilizando-se antissoros polivalentes e monovalentes, com ou sem indução de fases flagelares.

\section{RESULTADOS}

Encontrou-se Salmonella enterica em 17,0\% (18/106) dos D. aurita e 17,5\% (7/40) nos $\boldsymbol{D}$. albiventris. Nenhum dos animais apresentou lesões intestinais ou um quadro clínico - patológico gastroentérico. Dentre os 146 gambás, 71,7\% (76/106) D. aurita e $82,5 \%$ (33/40) D. albiventris foram submetidos à eutanásia, mesmo estando clinicamente saudáveis, pois 96 desses eram filhotes, os quais as mães tinham morrido por traumatismo e não havia destino para eles e os demais (13) estavam dentro de centro urbanos, muitas vezes no interior de residências. Eutanasiou-se 15,1\% (16/106) D. aurita e $10 \%$ (4/40) D. albiventris por terem sofrido processo traumático recente grave e $13,2 \%(14 / 106)$ dos D. aurita e 7,5\% (3/40) dos D. albiventris morreram naturalmente por esse mesmo motivo.

Quanto à origem dos animais, a maioria era de vida livre e habitavam áreas de mata ou parques próximo à população humana. Os gambás de cativeiro eram recolhidos pela população ou polícia de proteção ambiental e permaneciam nos zoológicos ou centros de triagem por um longo período, até serem submetidos à eutanásia. A positividade para Salmonella quanto ao sexo, faixa etária e procedência dos $\boldsymbol{D}$. aurita encontram-se na tabela 1 e dos $\boldsymbol{D}$. albiventris, na tabela 2 .

Nos D. aurita, encontrou-se Salmonella enterica no intestino delgado (ID) de $50 \%$ dos positivos, $88,9 \%$ no intestino grosso (IG) e em $66,7 \%$ na cloaca. Nos D. albiventris, encontrou-se em $42,8 \%$ no ID, $85,7 \%$ no IG e $71,4 \%$ na cloaca.

Nos $\boldsymbol{D}$. aurita, dentre os diferentes meios de cultura utilizados, recuperou-se Salmonella enterica simultaneamente do RV-XLT4 e TT-XLT4 em 50\% (9/ 18); somente em RV-XLT4 em 22,2\% (4/18); somente em TT-XLT4 em 11,1\% (2/18); concomitantemente em MC, VS-XLT4 e TT-XLT4 de 11,1\% (2/18); somente em MC em 5,5\% (1/18). Nos D. albiventris, recuperou-se essa bactéria somente do RV-XLT4 em 42,8\% (3/7); em VS-XLT4 e TT-XLT4 de 28,6\% (2/7) e simultaneamente em MC, VS-XLT4 e TT-XLT4 de 28,6\% (2/7).

Nos $\boldsymbol{D}$. aurita, da espécie $\boldsymbol{S}$. enterica, as subespécies encontradas foram: diarizonae com $11,1 \%$ $(2 / 18))$, houtenae e enterica com $5,5 \%$ cada um (1/18).
Tabela 1 - Fatores associados ao isolamento de Salmonella enterica em Didelphis aurita do Estado de São Paulo, Brasil.

\begin{tabular}{|c|c|c|c|}
\hline \multicolumn{2}{|c|}{ Didelphis aurita } & \multirow{2}{*}{$\begin{array}{c}\mathrm{N} \\
(\% \text { animais })\end{array}$} & \multirow{2}{*}{$\begin{array}{c}\mathrm{N} \\
(\% \text { positivo }) \\
13(18,6)\end{array}$} \\
\hline Jdode & Filhote & & \\
\hline Idade & Subadulto e adulto & $36(34,0)$ & $5(13,9)$ \\
\hline \multirow{2}{*}{ Sexo } & Macho & $54(51,0)$ & $8(14,8)$ \\
\hline & Fêmea & $52(49,0)$ & $10(19,2)$ \\
\hline \multirow{2}{*}{ Região } & Grande São Paulo & $73(69)$ & $5(6,8)$ \\
\hline & Interior e Litoral & $33(31,0)$ & $13(39,4)$ \\
\hline \multirow{2}{*}{ Origem } & Cativeiro & $16(15,0)$ & $14(87,5)$ \\
\hline & Vida livre & $90(85,0)$ & $4(4,4)$ \\
\hline
\end{tabular}

Na subespécie $S$. enterica enterica, o sorotipo mais frequente foi o Newport, encontrado em 83,3\% (15/18), seguido por Typhimurium e Cerro com 5,5\% cada um (1/18). Em um mesmo animal, isolou-se $\boldsymbol{S}$. enterica subsp. diarizonae, $\boldsymbol{S}$. enterica subsp. houtenae e o sorotipo Newport; e em outro a associação de Newport e Cerro.

Nos D. albiventris, o sorotipo mais prevalente foi também o Newport, que foi isolado em 71,4\% (5/7), seguido pelo Typhimurium, Bareilly e Thompson com 14,3\% (1/7) cada um. Isolou-se Bareilly e Thompson de um mesmo animal.

Quanto ao perfil bioquímico, a S. enterica subsp. diarizonae e $\boldsymbol{S}$. enterica subsp. houtenae apresentaram L(lisina), $\mathrm{H}\left(\mathrm{H}_{2} \mathrm{~S}\right)$, MT(motilidade), $\mathrm{O}$ (ornitina), C(citrato), La(lactose), Mn(manitol), $\mathrm{A}$ (arabinose), So(sorbitol), Ml(maltose) e VM(vermelho de metila) positivos; I(indol), U(uréia), F(fenilalanina), Sa(sacarose), VP(Voges-Proskauer) e G(gelatina) negativos (perfil 1). No sorotipo Newport, observaramse algumas amostras com o perfil 1 e outras com resultados iguais aos anteriores, exceto La negativa (perfil 2), C e La negativos (perfil 3) e La e A negativos

Tabela 2 - Fatores associados ao isolamento de Salmonella enterica em Didelphis albiventris do Estado de São Paulo, Brasil.

\begin{tabular}{llcc}
\hline \multicolumn{2}{l}{ Didelphis albiventris } & $\begin{array}{c}\text { N. } \\
\text { (\% animais) }\end{array}$ & $\begin{array}{c}\text { N. } \\
\text { (\% positivo) }\end{array}$ \\
\hline \multirow{2}{*}{ Idade } & Filhote & $32(80,0)$ & $6(18,8)$ \\
& Subadulto e adulto & $8(20,0)$ & $1(12,5)$ \\
\multirow{2}{*}{ Sexo } & Macho & $24(60,0)$ & $4(16,7)$ \\
& Fêmea & $16(40,0)$ & $3(18,8)$ \\
\multirow{2}{*}{ Região } & Grande São Paulo & $4(10,0)$ & $1(25,0)$ \\
\multirow{2}{*}{ Origem } & Interior e Litoral & $36(90,0)$ & $6(16,7)$ \\
& Cativeiro & $2(5,0)$ & $0(0.0)$ \\
& Vida livre & $38(95,0)$ & $7(18,4)$ \\
\hline
\end{tabular}

Ciência Rural, v.41, n.3, mar, 2011. 
(perfil 4); o sorotipo Typhimurium, a S. enterica subsp. enterica e o sorotipo Thompson com perfil 2; e o sorotipo Bareilly perfis $2 \mathrm{e} 3$.

\section{DISCUSSÃO E CONCLUSÃO}

A frequência de isolamento de Salmonella enterica em $\boldsymbol{D}$. aurita de 17\% (18/106) e em $\boldsymbol{D}$. albiventris de 17,5\% (7/40) foi semelhante entre si e mais baixa que a encontrada em isolamento de suabes cloacais de D. virginiana, realizados por TRIGPEN \& MOORE (1975), que encontraram 70\% (39/56) e 60\% (30/50) de positividade e feito por PIÑA et al. (2002) com 29\% (5/17). ADESIYUN et al. (1998) também encontraram positividade de $29 \%$ (5/17) proveniente de fezes de $\boldsymbol{D}$. marsupialis.

A existência de Salmonella no ID e IG constatam que estes animais são portadores dessa bactéria, sendo que a sua presença na cloaca indica que esses também estavam eliminando o agente no meio ambiente. Sendo assim, mesmo que a frequência de isolamento seja mais baixa que a observada na literatura, essas espécies brasileiras de gambás podem ser importantes carreadores dessa bactéria para outros animais selvagens, domésticos e seres humanos.

No presente trabalho, nenhum dos animais avaliados apresentou lesões intestinais; sendo assim, os D. aurita e os D. albiventris podem ser considerados reservatórios desta bactéria na natureza. Outros estudos demonstram que os $\boldsymbol{D}$. virginiana clinicamente saudáveis também podem albergar diferentes sorotipos de Salmonella do trato digestório (TRIGPEN \& MOORE, 1975; PIÑA et al., 2002; JIJÓN et al., 2007), bem como os D. marsupialis (ADESIYUN et al., 1998).

Quanto aos D. aurita, os provenientes de cativeiro apresentaram uma alta positividade, sendo que um grande percentual desses eram filhotes. Não há como determinar se eles já vieram da natureza infectados ou foram contaminados dentro dos centros de triagens ou zoológicos por alimentos, contato com outros animais ou humanos. JJJÓN et al. (2007) relatam que mamíferos órfãos que são alimentados com papas através de utensílios sem uma boa desinfecção podem desenvolver esta bactéria. Quanto aos D. albiventris, a maior positividade foi observada em animais de vida livre. Uma vez que esses animais frequentam o ambiente selvagem e o doméstico, eles podem transmitir Salmonella para outros animais selvagens, domésticos e contaminar água e alimentos.

De acordo com a técnica de isolamento, a suspensão em caldo RV seguido do plaqueamento em XLT4 foi a metodologia que permitiu maior recuperação de Salmonella enterica, seguido pelo caldo TT em XLT4. Com relação às provas bioquímicas utilizadas, pode-se concluir que apresentam uma ótima discriminação para o gênero Salmonella, já que todas as amostras que foram bioquimicamente compatíveis para esta bactéria apresentaram sorotipagem positiva. No entanto, a caracterização bioquímica das amostras através da determinação de um perfil não é eficiente, pois muitos sorotipos e subespécies diferentes apresentam as mesmas características, enquanto sorotipos iguais apresentam diferentes perfis.

Neste estudo, o sorotipo Newport foi o mais prevalente nas duas espécies de gambá. Em $\boldsymbol{D}$. marsipialis da ilha de Trindade na costa da Venezuela, este também foi o sorotipo predominante (ADESIYUN et al., 1998). Em D. virginiana, Newport já foi também isolada (PIÑA et al., 2002).

TRIGPEN \& MOORE (1975) isolaram seis sorotipos diferentes em D. virginiana, sendo eles Typhimurium, Bern, Infantis, Anatum, Give e Rubislaw, provenientes do intestino de animais saudáveis e do sangue, pulmões, fígado, rins, baço e intestinos de gambás clinicamente doentes. Esses autores constataram que Typhimurium e Bern eram os sorotipos mais patogênicos, pois foram encontrados com maior frequência no sangue e vísceras. No presente trabalho, isolou-se Typhimurium de dois animais clinicamente saudáveis.

Em um D. aurita, isolou-se $S$. enterica subsp. houtenae. RUNKEL et al. (1991) realizaram isolamento de Salmonella do trato biliar de D. virginiana e em todos os animais positivos foi encontrada esta subespécie. Através deste dado, esses autores estabeleceram que os gambás são reservatórios da bactéria no trato biliar. As demais subespécies e sorotipos isolados no presente estudo (S. enterica subsp. diarizonae, sorotipo Cerro, Bareilly e Thompson) ainda não haviam sido descritos em gambás.

Em um estudo realizado em humanos, no Estado de São Paulo, foram identificados 3.554 isolados de Salmonella de infecções gastroentéricas (FERNANDES et al., 2006). A Salmonella enterica subsp. enterica e o sorotipo Typhimurium foram os mais frequentemente isoladas em crianças, e o sorotipo Newport e a Salmonella enterica subsp. houtenae também foram identificados. O sorotipo Bareilly (COWDEN et al., 2003), Cerro (MAMMINA et al., 2000) e Thompson (LINARES et al., 1984) também já foram responsáveis por causar infecções em humanos.

Através deste trabalho, pode-se comprovar a presença de Salmonella enterica no trato intestinal de D. aurita e D. albiventris no Brasil. Essas informações contribuem para o conhecimento da epidemiologia das salmoneloses neste país, já que estes animais são comumente encontrados em áreas urbanas e rurais próximos à civilização humana, bem como em florestas.

Sendo assim, os veterinários e tratadores de zoológicos, criadouros e centros de triagem que 
tem contato com esses animais e com suas excretas devem saber do risco de contaminação, necessitando assim de apropriadas práticas de higiene. As fezes dos gambás podem contaminar água e alimentos fornecidos para outros animais selvagens, domésticos e inclusive para os seres humanos.

\section{AGRADECIMENTOS}

Aos médicos veterinários Adauto Veloso Nunes e Rodrigo Hidalgo Teixeira do Zoológico Quinzinho de Barros (Sorocaba - SP), à médica veterinária Dafne Neves do Departamento de Parques e Áreas Verdes (São Paulo - SP), ao médico veterinário Marcelo da Silva Gomes do Zoológico de São Bernardo do Campo (São Bernardo do Campo - SP), à médica veterinária Liliane Milanello do Parque Ecológico do Tiête (São Paulo - SP) e ao médico veterinário José Henrique Fontenelle do Orquidário de Santos (Santos - SP), pela disponibilização dos animais para este estudo.

Ao Conselho de Desenvolvimento Científico e tecnológico $(\mathrm{CNPq})$, pelo apoio financeiro.

\section{COMITÊ DE BIOÉTICA}

Este estudo foi submetido e aprovado pelo Comitê de Bioética da Faculdade de Medicina Veterinária e Zootecnia (FMVZ) da Universidade de São Paulo (USP) com protocolo $\mathrm{N}^{\circ}$ 686/2005. O Instituto Brasileiro do Meio Ambiente e dos Recursos Naturais Renováveis (IBAMA) concedeu a autorização para captura, coleta e transporte de material zoológico de Didelphis sp. sob o n.086/05.

\section{REFERÊNCIAS}

ADESIYUN, A.A. et al. Some bacterial enteropathogens in wildlife and rancing pigeons from Trinidad. Journal of Wildlife Diseases, v.34, n.1, p.73-80, 1998. Disponível em: $\langle$ http://www.jwildlifedis.org/cgi/reprint/34/1/73>. Acesso em: 20 jul. 2010.

CAMPOS, L.C. Salmonella. In: TRABULSI, L.R. et al. Microbiologia. São Paulo: Atheneu, 1999. p.229-234.

CERQUEIRA, R.; LEMOS, B. Morphometric differentiation between Neotropical black-eared opossums, Didelphis marsupialis a D. aurita (Didelphimorphia, Didelphidae). Mammalia, v.64, n.3, p.319-327, 2000. Disponível em: $<$ http://www.deepdyve.com/lp/de-gruyter/morphometricdifferentiation-between-neotropical-black-eared-opossumscv993uNjU2>. Acesso em: 20 jul. 2010.

CERQUEIRA, R. The distribution of Didelphis in South America (Polyprotodontia, Didelphidae). Journal of Biogeography, v.12, p.135-145, 1985.

COWDEN, J.M. et al. Outbreak of Salmonella Bareilly infection in Great Britain - results from the case-control study. Eurosurveillance, v.7, n.44, p.2316, 2003. Disponível em: <http:/ /www.eurosurveillance.org/ViewArticle.aspx?ArticleId=2316>. Acesso em: 21 out. 2010.

FERNANDES, S.A. et al. Salmonella serovars isolated from humans in São Paulo State, Brazil, 1996-2003. Revista do Instituto de Medicina Tropical de São Paulo, v.48, n.4, p.179-184, 2006. Disponível em: <http://www.scielo.br/ scielo.php? script = sci_arttext\&pid=S0036$46652006000400001 \& \operatorname{lng}=e n \& n r m=i s o \& t \operatorname{lng}=e n>$. Acesso em: 21 out. 2010. doi: 10.1590/S0036-46652006000400001.

FINNIE, E.P. Monotremes and Marsupials (Anatomy). In: FOWLER, M.E. Zoo and wild animal medicine. 2.ed. Philadelphia: Saunders, 1986. Cap.36, p.558-560.

HUNSAKER, D. Ecology of new world marsupials. In: HUNSAKER, D. The biology of marsupials. 3.ed. Estados Unidos: Academic, 1977. p.95-153.

JIJÓN, S. et al. Salmonella enterica isolated from wildlife at two Ohio rehabilitation centers. Journal of Zoo and Wildlife Medicine, v.38, n.3, p.409-413, 2007. Disponível em: <http:/ / ww w.bioone.org/doi/ful1/10.1638/10427260\%282007\%2938\%5B409\%3ASEIFWA\%5D2.0.CO\%3B2>. Acesso em: 15 jul. 2010. doi: 10.1638/10427260(2007)38[409:SEIFWA]2.0.CO;2.

LINARES, A.P. et al. Febrile gastroenteritis due to Salmonella Thompson - report of an outbreak. Western Journal of Medicine, v.141, n.2, p.203-205, 1984. Disponível em: <http:/ /www.ncbi.nlm.nih.gov/pme/articles/PMC1021737/>. Acesso em: 21 out. 2010.

MAMMINA, C. et al. Presença endémica de Salmonella enterica de serotipo Cerro no Sul da Itália. Eurosurveillance, v.5, n.7, p.28, 2000. Disponível em: <http://www.eurosurveillance.org/ ViewArticle.aspx?ArticleId=28>. Acesso em: 21 out. 2010.

OROZCO, L. et al. Animal and environmental impact on the presence and distribution of Salmonella and Escherichia coli in hydroponic tomato greenhouses. Journal of Food Protection. v.71, n.4, p.676-683, 2008. Disponível em: <http:// www.ingentaconnect.com/content/iafp/jfp/2008/00000071/ 00000004 art0000 1 ?token $=00551 \mathrm{f} 64 \mathrm{dcc} 22 \mathrm{c} 2330 \mathrm{c} 6 \mathrm{efa} 7 \mathrm{e} 442 \mathrm{f} 20$ 67217676344442e4976457a4034687627502b333e3568263c2be79d . Acesso em: 21 out. 2010.

PETRIDES, G.A. Sex and age determination in the opossum. Journal of Mammalogy, v.30, n.4, p.364-378, 1949.

PIÑA, H.A.R. et al. Isolation of Salmonella enterica and serologic reactivity to Leptospira interrogans in opossum (Didelphis virginiana) from Yucatán, México. Revista do Instituto de Medicina Tropical de São Paulo, v.44, n.4, p.235-237, 2002. Disponível em: <http://www.scielo.br/ scielo.php ? s cript $=\mathrm{sci}$ art text\&pid=S 0036 $46652002000400011 \& \operatorname{lng}=\mathrm{en} \& \mathrm{nrm}=\mathrm{iso} \& \operatorname{tlng}=\mathrm{en}>$. Acesso em: 15 jul. 2010. doi: 10.1590/S0036-46652002000400011.

RUNKEL, N.S. et al. Salmonella infection of the biliary and intestinal tract of wild opossums. Laboratory Animal Science, v.41, n.1, p.54-56, 1991.

TRIGPEN, J.E.; MOORE, A.J. Opossums as a revervoir for Salmonellae. Journal American Veterinary Medicine Association, v.167, n.7, p.590-593, 1975.

VILLAFAÑE, I.E.G et al. Assessment of the risks of rats (Rattus norvegicus) and opossums (Didelphis albiventris) in different poultry-rearing areas in Argentina. Brazilian Journal of Microbiology, v.35, p.359-363, 2004. Disponível em: <http:/ $/ \mathrm{www}$. scielo.br/scielo.php? script $=$ sci_arttext\&pid $=$ S1 1517 $83822004000300017 \& \ln g=e n \& n r m=i s o \& t \operatorname{lng}=e n>$. Acesso em: 21 out. 2010 . doi: 10.1590/S1517-83822004000300017. 